\title{
Trafficking of people. human trafficking
}

\begin{abstract}
Introduction: Trafficking in persons is a very old, long-standing global phenomenon, which has involved many countries in their histories and cultures but which has reappeared on the international agenda since the 1990s.
\end{abstract}

Objective: To carry out an update on the subject from a medical, social, cultural and ethical point of view.

Material and methods: A search was made in different search engines of importance for medicine, such as: Infomed. Lilacs, Medline and others. Results: The issue before us is very relevant and current at this time and it is a crime so widespread in the world against human rights that it is considered the slavery of the 21 st century, and it is among the three illegal and most lucrative activities for organized crime, According to data from both the United Nations and the International Labor Organization, more than 2.5 million people are victims of human trafficking, whether subjected to sexual or labor exploitation, servitude, organ trafficking, or destined to begging and war . The impact of trafficking on its victims, especially on women and girls, is devastating. In addition to coercion and frequent physical violence, there are serious consequences for women victims subject to sexual exploitation, such as sexually transmitted infections, transmission of HIV/AIDS, forced abortions, etc.

Introduction: It is human trafficking It is a very old world phenomenon, of that date that has involved many countries in their histories and in their cultures but that is reappeared in the international calendar starting from the decade of 1990.

Objective: To carry out to bring up to date on the topic from the medical, social, cultural and ethical point of view.

Material and methods: It was carried out a search in the different searchers of importance for the medicine, such as: Infomed, Lilacs, Medline and others. Results: The topic that occupies us has great validity and present time in these moments and it is such an extended crime in the whole world against the human rights that the slavery of the XXI century is considered, and it is between the three illegal and more For more information about the organized crime, according to the Organization of the United Nations, about 2.5 million people are victims of it labor exploitation, servitude, traffic of organs, or dedicated to the mendicity and the war. The impact of it treats her in their victims, especially in the women and the girls it is devastating. Besides the coercion and the frequent physical violence, serious sequels exist in the women victims subject to the sexual exploitation, like it is the case of the infections of sexual transmission, the transmission of the HIV/AIDS, forced abortions, etc.

Keywords: Trafficking in persons, society, history, culture, It is about people
Volume 9 Issue 2 - 2018

\author{
Miguel Lugones Botell C \\ Specialist I and II Degree in Gynecology and Obstetrics, Doctor \\ of Medical Sciences, University Polyclinic, Cuba
}

Correspondence: Dr. Miguel Lugones Botell C, Specialist I and II Degree in Gynecology and Obstetrics. Full Professor Master of Science and Auxiliary Researcher, Doctor of Medical Sciences, University Polyclinic, 26 de Julio, Playa Municipality, Havana, Cuba,Email lugones@infomed.sld.cu

Received: December 21, 2017 | Published: March 15, 2018

\section{Introduction}

Human trafficking is a global phenomenon very old, longstanding, which has involved many countries in their stories and their s cultures, but that reappeared on the international agenda as of the $1990 \mathrm{~s} .{ }^{1-3}$ It is -as it is currently referred to -an old problem with a new name. ${ }^{1}$

Human trafficking is a crime so widespread throughout the world human rights which is considered the slavery of XXI century and is among the three illegal activities more lucrative for organized crime, after drug trafficking and arms $;^{1}$ and it is , in turn, the product of a deprivation, mainly, of historical, economic, social and cultural rights.

Today, according to data from both the United Nations (UN) and the International Labor Organization (ILO), more than about 2.5 million people are victims of trafficking in persons, whether subjected to sexual or labor exploitation, servitude, organ trafficking, or destined to begging and war. ${ }^{1}$

During era s previously, women and girls, particularly African and indigenous, were uprooted from their places of origin and traded as labor, servitors and / or as sexual objects. But trafficking as a sociocultural problem began to be recognized in the late nineteenth and early twentieth century's through what was called 'White Traffic', a concept that was used to refer to the mobility and trade of white, European and American women, to serve as prostitutes or concubines in Arab, African or Asian countries..$^{2-4}$

Trafficking in persons constitutes one of the most serious violations of human rights and fundamental freedoms, and is in turn a product of deprivation, mainly, of economic, social and cultural rights. ${ }^{5}$

The situation of vulnerability suffered by millions of people in the world, who due to their age, sex, race, social, economic, cultural or political circumstances, find great difficulties to exercise their rights and develop fully in our societies, makes them fall in the networks of abuse and exploitation, often in search of a more dignified life. These difficult living conditions, mainly the result of social, economic and cultural segregation, tend to provide even more grounds for discrimination and marginalization, which increases the risk of trafficking; likewise, in most cases, tolerance and political and judicial 
complicity of the security forces, as well as the lack of training and perspective of the rights of the different operators and competent authorities to detect and investigate trafficking cases. ${ }^{5}$

The trafficking of women and prostitution dates back to the time of the conquest when Spaniards, in compliance with the law of war, took or handed over the "booty of women" to the victor giving rise to the sex trade and creating establishments for its exercise.

In 1869 the Academy introduced the entry <trata $>$ in its Dictionary with reference to the trade of African slaves, the expression $<$ trafficking of whites $>$ of French origin was developed in the nineteenth century bourgeois society with a subversive sense as a counterpoint to the slave trade. Once slavery was officially abolished, the international community, driven by Anglo-Saxon reforming moralism, focused its interest on the question of pimping and the prostitution of women and girls. To refer to this phenomenon, Victorian society used expressions such as white. ${ }^{5}$

In 1904 the first agreement in this area was signed in Paris, the International Agreement to ensure effective protection against criminal trafficking called white slave trafficking, which was followed by other agreements and protocols in which the same term was used.

The phenomenon of trafficking reached such a high level that it prompted the creation of various treaties on this subject within the United Nations. For example, the Convention for the Suppression of Trafficking in Persons and the Exploitation of Prostitution (1949). ${ }^{6}$

After World War II, and gra In view of the increase in female migration, it became evident that the phenomenon of trafficking, far from having disappeared, had spread throughout the world and acquired various modalities. Thus, the term "white slave trade" was desuso because it no longer corresponded to the realities of displacement and trade of persons, and little to the nature and dimensions of the inherent abuses of this phenomenon. ${ }^{6}$

It is important to have conceptual clarity about the characteristics and definition of human trafficking and other related concepts:

\section{Concepts}

Trafficking in persons shall mean the recruitment, transportation, transfer, harboring or receipt of persons resorting to the use of force or other forms of coercion, abduction, fraud, deception, abuse of power or of a position of vulnerability or the granting or receipt of payments or benefits to obtain the consent of a person who has authority over another for purposes of exploitation. Exploitation shall include, at a minimum, the exploitation of the prostitution of others or other forms of sexual exploitation, forced labor or services, slavery or practices similar to slavery, servitude or the removal of organs. ${ }^{1,2,6,7} 71 \%$ of the victims are women and girls. ${ }^{7}$

Traffic: Profitable activity with the sale, exchange or purchase of things or with barter and loan of money. Negotiation. Transportation of people, animals or things. ${ }^{8}$

Trafficking: Illegal and immoral trafficking that tends to the exploitation of man, deprived of his own disposition, or to the woman, as a merchant of physical pleasure. In either case, freedom or honesty is traded for a certain price. Trafficking in blacks and trafficking in women are considered.

The main differences between trafficking and trafficking in persons are: (Table 1$){ }^{3}$

Trafficking of migrants: Trafficking has been defined as the "facilitation of the illegal entry of a person in a State of which said person is not a national or permanent resident in order to obtain, directly or indirectly, a financial benefit or other benefit of order material.

Table I Differences between trafficking and trafficking in persons

\begin{tabular}{|c|c|}
\hline About & Traffic \\
\hline $\begin{array}{l}\text { The relationship of the victim with } \\
\text { the trafficker is given coercively or by } \\
\text { means of a deception }\end{array}$ & $\begin{array}{l}\text { The relationship with the trafi singing } \\
\text { is given with the feeling of the victim }\end{array}$ \\
\hline $\begin{array}{l}\text { It is not necessary to cross borders to } \\
\text { carry out human trafficking }\end{array}$ & $\begin{array}{l}\text { oFor there to be human trafficking } \\
\text { there must be a cross-border teras }\end{array}$ \\
\hline $\begin{array}{l}\text { The main victims of trafficking are } \\
\text { children and women }\end{array}$ & $\begin{array}{l}\text { The main trafficked persons are male } \\
\text { migrants }\end{array}$ \\
\hline
\end{tabular}

The risks and damages are presented during the entire time the person is trafficked, more than suffer serious consequences in their health, even after the crime has been committed

The greatest risks and damages are presented du during the transfer

Sometimes there is a transaction of money when transferring the victim A transaction is made tion of money (of being transferred), since generally as a consequence of the do of the the nance is given at the place of person destination

Usually the relationship between the victim and the tra This is more prolonged and complex, and gives at the same time as the exploitation of the tima The relationship between the per
trafficked and trafi singing comes to an end when the migrant ga to the place of destination

The discourses on the 'trafficking of whites' were used and even monopolized by the abolitionist movement of prostitution, whose struggle was centered on its eradication, considering it a form of slavery for women. Their actions crystallized on the global agenda through various international agreements for the suppression of trafficking, developed from 1904 until 1949, the year in which the General Assembly of the United Nations approved the Convention for the Suppression of Trafficking in Persons and the exploitation of the prostitution of others. ${ }^{2,3}$

At the beginning of the $1980 \mathrm{~s}$, after several years of silence, speeches about the trafficking of women for sexual exploitation took force in different sectors, due, among other reasons, to the increase in transnational female migration that had been brewing since the end of the $70 \mathrm{~s}$, within which it seems to increase, or at least become more evident, the incidence of the phenomenon in almost all regions of the world and in many different ways. ${ }^{2}$

At that time, the term "human trafficking" or "human trafficking" began to be used to refer to international trade in women and minors, without reaching a consensus definition of the phenomenon. Trafficking of persons is the translation into Spanish of the English term 'trafficking in persons', which were translated and introduced to Latin America.

The fight against trafficking in persons and specifically women requires a multidimensional approach and a social and cultural analysis of each nation involved in it, as well as the active participation of several federal, state and municipal institutions along with society entities civil.

The international process to define and tip the trafficking of persons $^{10}$ 


\section{Vienna,Austria}

Conference on Human Rights. For the first time, information is collected based on cases of trafficking of foreign women processed in different European countries in which human rights violations were observed. As a result of this Conference it was determined that trafficking in Persons is a violation of fundamental rights.

\section{995 Beijing, China}

Fourth International Conference on Women: The first cases of trafficking in women for the purpose of exploitation are presented sexuality, particularly of women in Colombia, Benin and the Balkans. As a result, the issue of trafficking in persons is included in two articles of the Beijing declaration.

\section{Nineteen ninety six}

On the initiative of the United Nations Rapporteur on Violence against Women, Radica Coomasasway, the first global diagnosis on the issue of trafficking is carried out, gathering information from the different states and authorities, international organizations and NGOs on cases and victims. The results of this research convinced many governments of the need to combat the problem through the elaboration of specific international instruments.

\section{7-2000}

Representatives of about one hundred states work in Vienna on the elaboration of the Convention against Transnational Organized Crime and the Trafficking Protocol.

\section{December 2000 Palermo, Italy}

In the framework of a World Conference convened by the UN, 1_7 countries sign the United Nations Convention against Transnational Organized Crime and its two Supplementary Protocols, one against Trafficking in Persons, especially Women and Children (see Annex 1), and a second against the Illicit Trafficking of Migrants by Land, Sea and Air.

\section{September 2003}

The Convention enters into force, having been ratified by many States. The same applies to the Trafficking Protocol on December 25, 2003

\section{Impact and consequences of trafficking in persons ${ }^{10,11}$}

Trafficking undoubtedly represents a serious violation of human rights and the dignity of people. It is also a highly lucrative criminal activity, in which they are frequently involved organized networks often associated with other criminal activities such as migrant smuggling; drug trafficking, money laundering and arms trafficking. Trafficking in persons thus becomes an important issue of national and international security and even public health. It also constitutes a serious social and cultural problem when people from different countries with different cultures intervene. In health, it is also a very important issue, because in this way diseases that are endemic to each country can be transmitted.

The impact of trafficking on its victims, especially on women and girls, is devastating. In addition to coercion and frequent physical violence, there are serious consequences for women victims subject to sexual exploitation, as is the case of sexually transmitted infections, the transmission of HIV/AIDS, forced abortions, the propensity to alcoholism and drug use and even anonymous and unpunished deaths at the hands of organized crime.

Women victims of trafficking are socially and culturally rejected but massively used; "Invisible" due to the secrecy that surrounds them; absolutely defenseless, unprotected and extorted in all aspects and even points that are difficult to bear.

The psychological impact is not minor, from insecurity and loss of self-esteem to more permanent traumas caused by abuse and physical and mental violence. The sequel of psychological damage in children victims of trafficking is always difficult to overcome, and in many cases irreparable.

\section{Consequences for victims ${ }^{11,12}$}

a. Serious violation of human rights

b. Physical and / or sexual and / or psychological abuse

c. Prolonged or permanent physical or psychological harm

d. Death risk

e. Cosification of people

f. Reintegration difficulties

g. Stigmatization

\section{Consequences of trafficking in societies and their cultures $^{12-17}$}

i. Destabilization of the sexual and labor markets, generating unfair competition and social instability (particularly in those States where the sex industry is not penalized)

ii. Decomposition of the social fabric

iii. Recovery costs for victims

iv. Risks of affectation to the public health (STI, HIV / AIDS, Hepatitis BYC)

v. Proliferation and diversification of organized crime and generating conflict s territorial conflicts and violence s

vi. Money laundering with a clear impact on financial markets

vii. Increase in corruption

viii. Violation of existing national legislation (against sexual exploitation, labor laws, migratory laws, human rights, etc.)

Public health problems do not only arise in the context of contagion from sexually transmitted infections (STIs) and 'common' infectious diseases such as emerging and re-emerging problems of tuberculosis, HIV/AIDS, and Hepatitis B and C. Significant risk to public health, if due to the health systems decimated in most countries of origin, 1 'preventable diseases to countries of transit and destination where most of the medical staff has not had to deal with these pathologies previously.

We are then faced with a complex phenomenon that touches multiple angles: violence against women and children and the extreme violation of their rights, sexual and labor exploitation that tends to destabilize internal markets, migration frequently irregularly, networks national and transnational criminals who are an affront to the procurement of justice, public security and police investigation, education especially of adolescents and more generally the physical and mental health of societies. 
Some physical and mental symptoms of the victim of trafficking ${ }^{17-20}$

Psychosomatic reactions: headaches, neck, back or stomach pains, tremors, sweating, heart palpitations, sleep disorders, Immunosuppression, etc.

Physical evidence of abuse: Visible injuries from bumps, fractures, scars, other signs of untreated medical problems and injuries in areas not immediately visible

Psychological reactions: despair, anxiety, nightmares, chronic fatigue, excessive crying, general apathy, suicidal tendencies, selfinjury, explosive or severely inhibited anger, violently altered states of consciousness, amnesia, episodes of dissociation, reliving experiences, isolation, withdrawal, distrust, memory problems, etc.

Abuse and dependence of psychoactive substances: overdose, addiction, physical sequelae (brain, liver), infections by the use of syringes, drug dependency, alcoholism, high-risk behaviors such as unprotected sex, violence, crimes, etc.

Social reactions: feelings of isolation, loneliness, inability to establish or maintain significant relationships, distrust, rejection by family members or the community, risk of falling victim to trafficking.

\section{Trafficking in women, girls and children: a flagelo that} sees extend all over the world ${ }^{17-22}$

Due to its clandestine nature and lack of consensus in the definition and understanding of this phenomenon, it is extremely difficult to establish figures or statistics with precision. However, the International Organization for Migration (IOM) ${ }^{6}$ estimates that approximately one million men, women, boys and girls worldwide are deceived, sold, coerced or subjected to conditions similar to slavery under different conditions each year. Forms and in various sectors: construction, maquila, agriculture, domestic service, prostitution, pornography, sex tourism, servile marriages, child soldiers, organ trafficking, sale of children, among others, being women, girls and boys the sector more vulnerable

\section{General recommendations to combat trafficking in persons ${ }^{23-26}$}

In the first place, it is necessary to give visibility to the problem. Knowing how and where the trafficking is present, that is, the main countries involved in it, how it operates and who its victims are, is essential both to sensitize each society and promote a culture of denunciation in it, as well as to begin propose solid public policy actions that address this problem from a multidimensional lens. The studies, diagnoses and exchange of information between the different institutions involved are usually very useful for this purpose. For all these reasons, it would be important to place the issue of trafficking in persons on the national public agenda of each country involved, as well as in the international one, and to work closely with all actors at the political, legislative and operational levels, as well as to strengthen international cooperation.

Specific legislation on trafficking in persons is fundamental. This legislation should have a global approach, such as that contained in the Protocol that allows progress towards what some institutions mention as the three P: prosecution of traffickers (or law enforcement), protection of victims and prevention of trafficking.

The training of the different sectors involved - public and private institutions as well as different sectors of civil society - about trafficking, how it operates, how to prevent it, how to identify and assist the victims and finally some guidelines for effective combat it is of crucial importance.

It is also key to consider the importance of care and attention to victims, regardless of their origin. The greatest challenges are identification, immediate assistance and protection, and protection and recovery measures in the medium term.

The identification of victims suggests looking for them among migrants insured or detected in border controls or points of entry; irregular migrants detected by police bodies through investigations, raids or complaints; people assisted by civil organizations, churches, public health institutions or migrant shelters; people looking for help with consulates, relatives or friends.

In terms of assistance and immediate protection, it will be necessary to address medical, psychological, lodging and food, legal assistance and social reintegration or reintegration actions, including possibilities of residence in the country of destination, residence in a third country or return to its place of origin, always considering the risks that this implies in an individualized way.

In this framework, the establishment of shelters or the use of existing ones, to provide a physical place of temporary assistance that provides a safe and adequate environment to stabilize the victim, prevent further damage and facilitate their recovery plays a key role.

In the measures of recovery and social reintegration we highlight the importance of counseling and emotional and psycho-social support, to face the trauma of abuse and exploitation of the victims (physical abuse, psychological abuse, sexual abuse, economic exploitation, induced use of alcohol and other substances, insecurity, loss of self-esteem). This is of paramount importance for the case of underage victims, for whom the psychological impact is much greater and lasting.

Legal assistance to victims will depend on the legislation that may be introduced and the possibility of initiating criminal and / or civil proceedings. Internal legislation may provide for the possibility of cooperating with the competent authorities, specialized forces or police forces, against perpetrators or the possibility of demands for compensation. It is important that the victim knows the implications and ramifications of any step he or she decides to take, as well as guaranteeing their rights and privacy. Other legal aspects refer to the recovery of documents (passport), divorce cases, claims for the restitution of children, possible request for temporary residence, possible request for refuge or asylum, a possible witness protection program, etc.

The action of the security forces is determinant in the issue of trafficking, not only in terms of law enforcement but also in the sphere of protection of the victims. Therefore, it is imperative that they become reliable spaces for victims of trafficking to seek help and the response is effective. If for some reason there is delay, corruption, complicity with the traffickers or criminalization of the victim, the effect will continue to discourage the denunciation of the perpetrators of this crime and thus hindering their persecution, punishment and eradication.

Finally, it is essential to improve and increase the cooperation of public institutions and between them and civil society. In other words, the strengthening of a coordination mechanism between various public institutions and the active participation of civil society entities will be decisive in order to obtain effective results in the fight against human trafficking. 


\section{In Cuba}

Cuba maintains its policy of "Zero Tolerance" against any form of trafficking in persons and other crimes related to sexual, labor or other exploitation, by strengthening the actions in the internal context and adopting measures aimed at raising prevention, the confrontation, severely punish the perpetrators and provide protection to the victims. In parallel, Cuba has increased international collaboration as a State Party to the various international legal instruments signed on this subject. ${ }^{7}$

\section{Cuban legal order}

The various legal instruments available to the country allow dealing with human trafficking and other behaviors associated with it such as pimping, prostitution, child pornography and prostitution, as well as other forms of exploitation, or sexual abuse.

The set of criminal types that sanction such behaviors is consistent with the spirit of the Palermo Convention, its Protocols and other international instruments of which Cuba is a Party.

\section{Final considerations}

Undoubtedly, the great levels of inequality that exist in various regions of the world, in economic, historical, cultural and social terms, favor the most aberrant expressions of violence and exploitation, of each other and others. ${ }^{17,18}$

From a gender perspective, it is fundamental to denaturalize power relations based on patriarchal cultural patterns that reproduce gender inequalities and favor the domination and ab use of one sex by the other. Each society must generate reflective awareness about these situations, eliminate sexist prejudices, and begin to delegitimize certain practices that are still accepted or tolerated and that constitute a clear violation of human rights. ${ }^{18}$

The right is certainly a fundamental tool to start making social and cultural changes in this regard. In this regard, the Argentine Republic, in response to the international commitments assumed, has enacted Law 26,364 in 2008, which aims to adopt measures to prevent and punish trafficking in persons, and to assist and protect its victims. Likewise, this norm was modified in December 2012 by law 26,842, with an important advance such as suppressing the requirement that mediate means such as deception, fraud, violence, threats or any other means of intimidation or coercion, abuse of authority or of another situation of vulnerability for the crime to be configured, and establishing that the consent given by the victim of the trafficking and exploitation of persons will not constitute in any case the grounds for exemption from criminal, civil or administrative responsibility of the perpetrators, participants, cooperators or instigators. The regulations also deepen in the adoption of public policies by different areas of the national State and provinces to work in a coordinated manner in the prevention of this crime and in the restitution of rights to victims. ${ }^{22}$

In addition, Decree 936/11 has been issued which prohibits "notices that promote sexual offer or make explicit or implicit reference to the request of persons destined to the sex trade, by any means, in order to prevent the crime of trafficking in persons. People for the purpose of sexual exploitation and the gradual elimination of forms of discrimination against women".

To all this we must highlight the importance of having a law to Prevent, Punish and Eradicate Violence against Women, such as Law 26,485 , a rule that promotes the removal of sexist cultural patterns, which expands and makes visible the different types and modalities of violence suffered by women, and provides an inter-institutional approach to gender-based violence, based on the comprehensiveness of the policies to be adopted.

As already noted, trafficking in persons is a complex crime,,${ }^{1-4}$ its consequences are also, so it requires a comprehensive approach, from prevention, punishment, protection and assistance, to begin to eradicate trafficking, dismantling criminal networks, creating conditions of dignified life so that all people can exercise their right to develop freely and fully, and generating networks of containment and opportunities for those who were victims to regain their rights and achieve their full social reintegration.

The fight to eliminate trafficking in persons is a long term process and many challenges require joint action and the commitment of all nations and all sectors. There must continue to promote a culture of social rejection towards the problem; establishing specific policies in the area of prevention and legislation creating effective and exemplary avoid impunity.

\section{Acknowledgements}

None.

\section{Conflicts of interest}

Authors declare there is no conflict of interest in publishing the article.

\section{References}

1. Casillas RR. Social and cultural aspects of human trafficking in Mexico aspects. INACIPE: National Institute of Penal Sciences Editorial. 2013.

2. Trafficking, story of a scourge. El Siglo.

3. National Commission of Human Rights. Trafficking. Mexico: CNDH. 2017.

4. Staff WMB: Historical tour of trafficking.

5. Iellimo M. Trafficking, an analysis from a gender perspective.

6. Manual on the investigation of the crime of human trafficking. United Nations Office on Drugs and Crime.

7. Ávila GG: Human trafficking. Granma newspaper.

8. Santo V. Dictionary of legal, political, social sciences and economics. Argentina: Editorial University, 1999. 840 p.

9. Caban ELAS G. encyclopedic dictionary or common law. Argentina: Editorial Healista, 2001. 191 p.

10. Espinosa TP, T Revino LH. Trafficking. Basics. American Commission of Women of the Organization of American States. International Organization for Migration Editorial Healista. 2006;117-123.

11. Ripoll Alejandra. Colombia: Semil lero for trafficking. J International Relations, Strategy and Security. 2008;3(1):175-186.

12. Cacho Lydia. Slaves of power: a journey to the heart of sex trafficking of girls and women worldwide. Collection Moment of Mexico. Mexico: Grijalbo/Process, 2013. 471 p.

13. Anguita Olmedo Concepción. Illegal trafficking in human beings for sexual and labor exploitation: slavery of the XXI century. Critique of Social Sciences and Law Magazin. 2007;15(1).

14. Bonatto G, Lerner G. Child sexual exploitation and trafficking: a view from the policies of restoration of rights. You treated us. Buenos Aires: The editors Juana, 2009. 43 p.

15. Butler J. Bodies that matter. On materials and discursive "sex" limits. Buenos Aires: PAIDOS, 2005. 60 p. 
16. Giberti E. The traffickingand its victims. J Public Prosecutions, Province of Buenos Aires. 2010;7(11):34.

17. Raymond. Janice, 10 Reasons for Not Legalizing prostitution. International Coalition against Trafficking in Women, 2003.

18. Molina ML. Sexual exploitation. Buenos Aires: Editorial Dunken, 2008. $118 \mathrm{p}$.

19. Couple E. Prostitution in Buenos Aires. Buenos Aires: Editorial Tor 1937. $43 \mathrm{p}$

20. Galdona J. Ethics and the meaning of life. Info DEIE, 1993. 4 p.

21. Trafficking. Key data.
22. Cuesta M, Oscar Julián, Castillo M, et al. Investigations on trafficking in persons and commercial sexual exploitation of children and teenagers. Proposals to raise awareness for prevention and means of communication Findings. 2015;12(23):251-273.

23. Jimenez AA. The meaning of life, enters the exam? Spanish J Pedagogy. 1994;198:247-256.

24. Rachels J. Introduction to moral philosophy. Mexico: Fondo de Cultura Economica. 2007.67-69 p.

25. Reis MA. Ethics of Human Rights. Heildelberg: Springer, 2014.22-26 p.

26. Santos CAM. Human trafficking and its ethical implications. 